\title{
A Servitization Process for Small and Medium-Sized Manufacturers
}

\author{
Yongse Kim, Heeju Lee, Jihoon Kim \\ Service Design Institute, Sungkyunkwan University, Suwon, Korea \\ Email: yskim@skku.edu
}

Received 13 June 2015; accepted 7 July 2015; published 14 July 2015

\begin{abstract}
To improve competitiveness of a manufacturing company through enhanced experience values of customers, service elements are added to a product. The servitization process could take many different routes reflecting various properties of the manufacturing firm and its business contexts. A comprehensive servitization process of the high-level strategy decision and the low-level specific product-service systems design method have been developed at the Service Design Institute of Sungkyunkwan Universty. The servitization case of a small furniture manufacturing company is described in this paper to demonstrate the utility of the servitization method.
\end{abstract}

\section{Keywords}

Product-Service Systems, Service Design, Servitization Process, Business Innovation

\section{Introduction}

Competitiveness of a manufacturing company goes through fast transitions these days. New product-oriented or technological advantages may not have a long sustaining duration as competing companies quickly catch up with due to openness in technological development. Moreover, customer wants are getting more comprehensive addressing total solutions for their needs beyond fragmented supports with hardware-driven provisions of manufacturers. More integrated solutions comprising hardware and software elements as well as service elements are desired by customers. Often their value appreciation trends undergo fast expansion, from economic and ecological to experience values. Thus, the manufacturing servitization and integrated delivery of service components as added values when providing products, are receiving a lot of attention these days [1] [2]. Innovative integration of service and product elements based on the company's business contexts, such as business environment, company's capability in terms of human and organizational strengths, and customer needs, could lead to business competitiveness. Thus, the manufacturing servitization into product-service systems received a lot of attention these days when people's experience values for both provider and receiver sides of services were critical. A comprehensive process of manufacturing servitization has been devised with higher-level strategy design process and lower-level product-service system design. Product-service systems design process includes value modeling and service concept design as well as stakeholders' experience evaluation of prototyping product-service systems. Strategy design process includes business context diagnosis and business model design including productservice eco-system design. This comprehensive servitization process has been applied to a small furniture man- 
ufacturing company in tight collaboration among the company, consultants and our research team. The paper will describe the servitization process of this company with great details.

\section{Double-Deck Servitization Process}

\section{Servitization Process}

A comprehensive process of manufacturing servitization has been devised with higher-level strategy design process and lower-level specific product-service system design. While both the high-level strategy process and the low-level specific PSS design process are composed of various tasks, going between high-level and lowlevel also happens more than once in an iterative manner as shown in Figure 1 where strategy process is shown in blueish color and PSS process in purple. Thus the servitization process is called as double-deck process. Overall one span of iteration would be composed 4 sub-processes.

First at the strategic planning level, a manufacturing company collects information on servitization and receives servitization introduction from external servitization experts. Then the company considers servitization and seek servitization potentials internally. If their interests build up, the company gets initial consultation with eperts. Often, servitization task force team is built before moving further. Together with servitization consulting experts, business contexts of the company are diagnosed from servitization perspective and servitization potentials are analysed.

Secondly moving down to specific PSS design level, key competencies of the company are analysed, and so do its products. For specific target product chosen, life cycle steps are analysed. Requirements of stakeholders are collected often with voices of customers. Then the core values of the stakeholders are identified using the frame-work of E3 value concept; economical, ecological and experience values [3]. Particularly, experience values of functional, social, emotional and epistemic concerns are identified to guide the servitization process. Next, product-service system concepts are designed. Specifically, this process includes journey map design, hierarchical value mapping where associations of value themes, their attributes [4] and specific service activities are reviewed from previous design cases. Also various product-service system cases are retrieved for referencing purposes. Then the a few service portfolios of several service concepts are generated and analysed to select service concept of servitization.

Thirdly, detailed design of a product-service system is conducted based on service concept selection. To obtain proper perception from potential customers, brand de-sign is done. Service journey map of specific service tasks is made and then detailed service activities are design and represented in the form of a service blueprint [5]. Functions of the product-service system are determined. By considering interactions between stakeholder activities and product-service system functions, affordances are identified to design touchpoint of product elements to support activities [6]. Then initial business models of the product-service system concept are designed. Prototype of the product-service system concept is made and customer experiences of the prototype are obtained with potential customers. Also experiences of service providers are evaluated as well. Business models are refined before moving up the high-level strategy design.

At the fourth sub-process of high-level, decisions on product-service system implementation are made including organizational redesign and eco-system partner identifications. Then overall impact including monetary expectation is to be assessed.

\section{Case Study of a Small Furniture Company}

\subsection{Business Context Diagnosis}

We now describe the servitization process of a small furniture company to illustrate the servitization process. Top Plan DNC, established in 2007, is a small-sized furniture manufacturer, which manufactures commercial

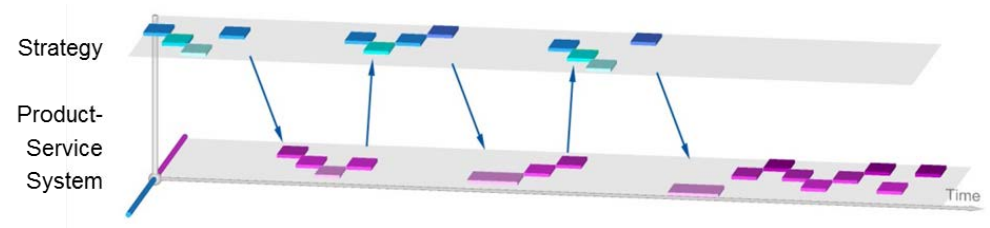

Figure 1. Double-deck servitization process. 
display furniture used for fashion brand flagship stores and department stores. Two servitization experts visited the company at their manufacturing site. They analysed current business context and core competencies. First, the location of the factory is the core potential of this firm due to accessibility and nice surrounding nature. They are located in furniture manufacture town, the suburbs of Seoul, a major city. Second, they have a customized-furniture manufacturing skill. Since they work for the fashion industry, which has quick seasonal changes, their core capabilities are speed assembly/installation process, commercially customized design and speedy manufacturing system. Third, they have two levels of clients. The first clients are interior design agencies, and the second clients are several fashion brands. Their business is B2B in its nature.

Business context of a company is diagnosed using three aspects; business environment, company's capability in terms of human and organizational strengths, and customer needs. Business Context Diagnosis of Top Plan DNC The products they produce are in its rather matured stages, thus servitization may lead improvement. Their business situation has peak-season and off-season as a part of fashion industry. But they have to maintain workforces throughout the year. This is a big motivation for them to seek off-season revenues possibly by adding service elements. In terms of their competencies, they have good designers and manufacturing and installation experts while their finance state is not so good. While there are increasing demands on customization in furniture market in general, they do not have strong B2C customer channels. Based on these analyses, servitization would be a proper strategy for them to increase their competitiveness. The diagnosis is shown in Figure 2.

\subsection{Product-Service System Concept Design}

By analyzing the furniture life cycle, starting from the manufacturing process to the end of removal, we find that the clients of the firm are not only fashion business, but also they rarely have home furniture customers. This means that they have the potential of the customized home furniture market. In this case of furniture manufacturer, we focus on pre-usage phase, which includes the production, selling, buying, delivering and installation. Currently this firm establishes B2B system, and their sales volumes are followed by off and peak seasons of fashion industry. To expand their business, the firm strives to find different stakeholders. Accordingly, we narrow down to home furniture production and selling steps. Requirements are obtained through customer experience research. Then, E3 values (economical, ecological, experience) are identified from the requirements. E3 Value can be used for stimulating to creative ideation. Also, requirement identification of existing products and manufacture systems is helpful to generate a new service design. Based on an interview of Top Plan DNC workers and home furniture user experience research, various requirements can be classified as E3 Value framework. The following functional, social, active emotional, reactive emotional and epistemic value themes are obtained as shown in Figure 3.

After reviewing activities associated with these value themes in the hierarchical value maps and service concepts used in other product-service system cases, a service port-folio of several service concepts has been devised. The overall service concept is to make the relationship between customers and Top Plan DNC. First customers are invited to Top Plan DNC for personalized DIY and Check my order services. Once relationships have been made, then the company goes into the home of customers with use information and check-up and replacement services first, then customization. As customers have desire of diversity and personalization in furniture service, a new innovative solution is providing personalized DIY furniture service. Personalised DIY design

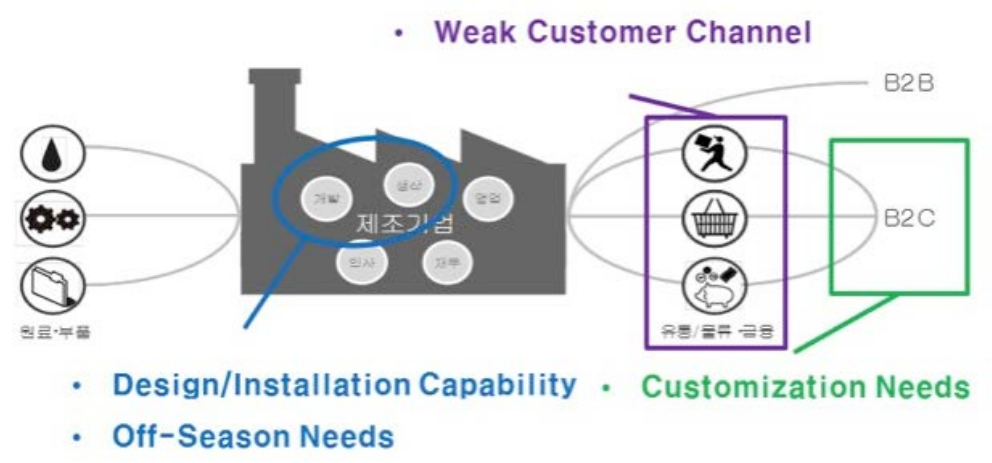

Figure 2. Business context diagnosis of top plan DNC. 


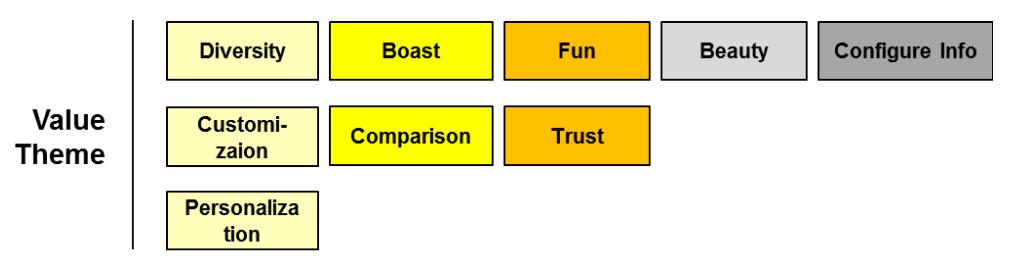

Figure 3. Value themes.

can be a modular design that customer can continuously replace modules. In detail, the firm can execute DIY furniture education to DIY community. Customers, who have an interest in the furniture manufacture process, will satisfy with viewing their own furniture. Also, experiencing education service will build relation-ships between the firm and customers. In order to keep a close relationship with customers, the firm will need to provide them door-to-door maintenance service. All these services are the way of forming customer trust.

\subsection{Product-Service System Detail Design and Prototyping}

The personalized DIY was given the brand name of 'Happiness Customizing Wood-work Shop". The intent is to motivate customers to create their happiness that suits their family with their own efforts in their own way at the manufacturing site of Top Plan DNC with the help of the skilful experts. Its logos with the brand name are shown in Figure 4. Then the overall customer journey map starting from applying for DIY and choosing kids furniture to DIY, driving and arriving at the site, DIY and bringing the furniture home, and usage. The details of the service including activities of customers and workers are designed in the service blueprint. Prototyping of the service design has been conducted with five families with elementary school kids. Evaluation of prototyping has been done using the Context-specific Experience Sampling and Analysis (CESA) method [7] where real-time experience evaluations of specific tasks done using smart phones. As shown in Figure 5, overall experiences are improved as DIY has been conducted compared to before actual DIY. Only when they go home and arrive in home, some drops in experience values are shown. However, it is noticed when they chose colors the experience value of familiarity and educational contribution went low.

\subsection{Product Touch Point Design: Color Selection}

With the prototyping test, need for improvement in color selection service has been noticed. For this service, E3 values have been identified. Functional values such as convenience, professional, efficiency, safety, and clean have been identified. Social value of uniqueness and active emotional values of fun and control are important as well as harmony of reactive emotional value. Then customized color selection service has been developed with its activities shown in Figure 6. However, it is noticed when they chose colors the experience value of familiarity and educational contribution went low. Service elements, one per service function, have been defined by interactions of stakeholder activities and functions. They are "convenient preparation", "painting explanation", "color consulting", "customized color selection", and "storing service element". Using function-task-interaction (FTI) Galvao and Sato [8], nine affordances are identified as shown in Figure 7: Allocate-ability, Show-ability, Match-ability, Takeout-ability, Place-ability, Paint-ability, Compare-ability, Bring-ability and Store-ability. And then, their affordance features are designed by transforming source affordance features obtained in the repository into target affordance features through analogical reasoning [6].

\subsection{Product Touch Point Design: Color Selection}

Following the design for affordance method [6], source affordance features are identified from the affordance feature repository. By analogical reasoning, source affordance features are transformed into target affordance features considering context information. In Figure 8, for specific affordance, affordance features retrieved are shown in the lower part while target affordance features sketched shown in the upper part. Then for each affordance, most suitable target affordance is identified by comparison. Through morphological chart method with the target affordance features, a touch-point product-element for customized color selection is to be designed as shown below in Figure 9. Note that depending on the number of participating families, flexible groupings of this module based color selection touch point can be made with effective participant-expert interaction as shown 


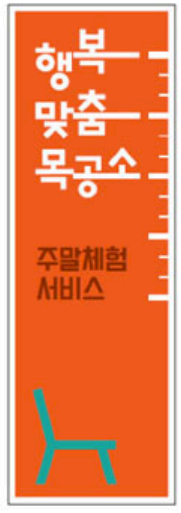

(C)
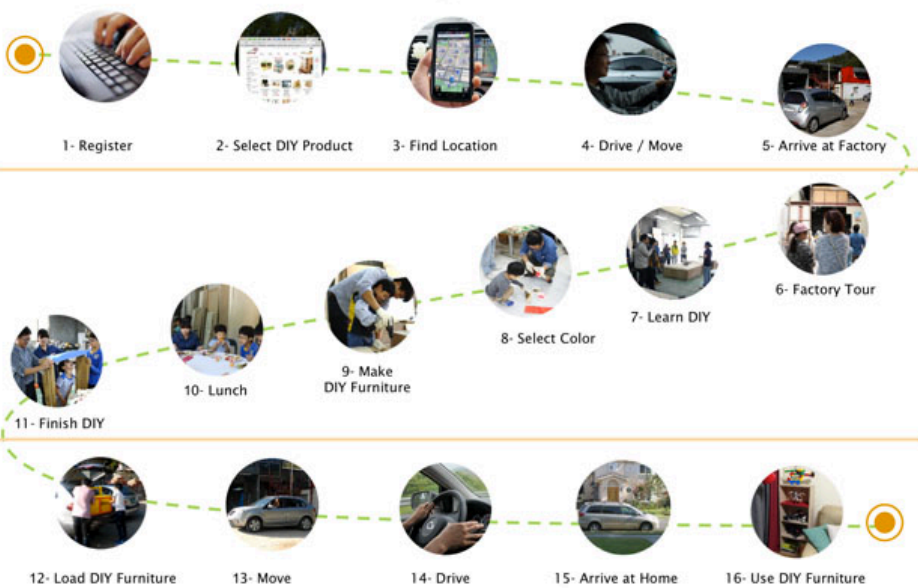

Figure 4. Service BR and identity and journey map.

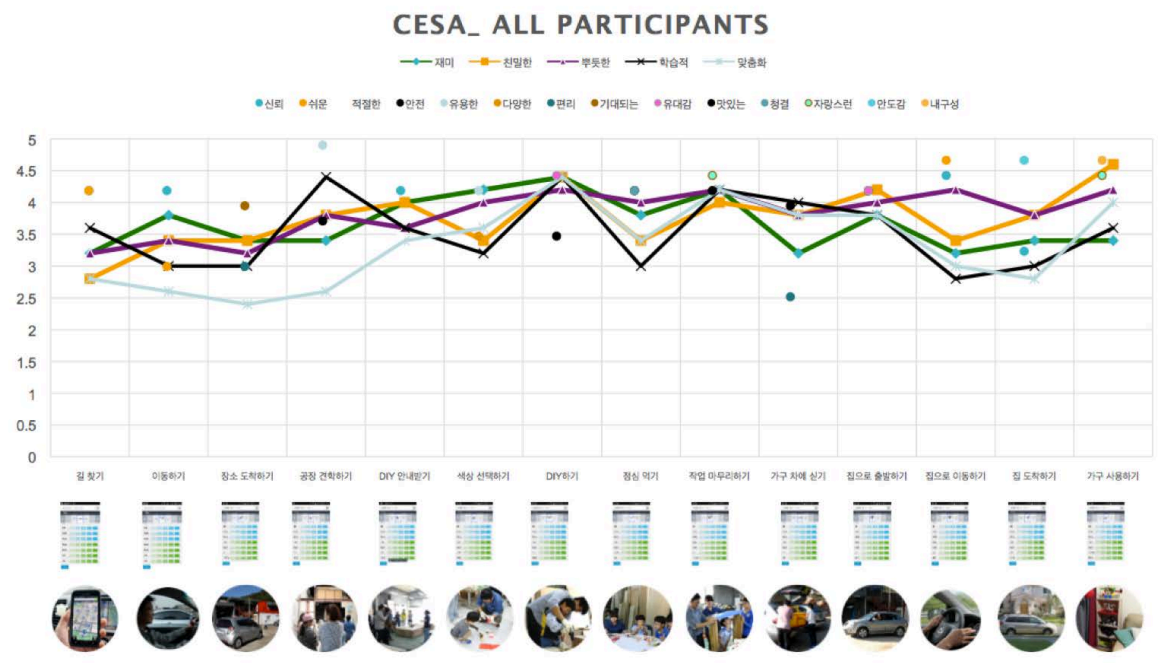

Figure 5. Experience evaluation summary of first prototyping.

\begin{tabular}{|c|c|c|c|c|c|c|c|c|c|c|c|c|c|c|c|}
\hline Pancernt-1 & & & & 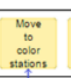 & $\begin{array}{l}\text { and } \\
\text { sud } \\
\text { sond }\end{array}$ & 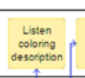 & 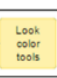 & show & 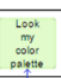 & 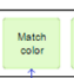 & atiston & 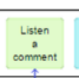 & 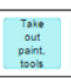 & 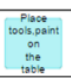 & 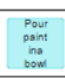 \\
\hline $\begin{array}{ccc}\text { cotert } \\
\text { ent }\end{array}$ & 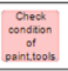 & 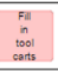 & 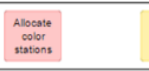 & 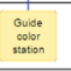 & & $\begin{array}{c}\text { Exom } \\
\text { coror }\end{array}$ & & 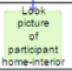 & 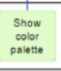 & 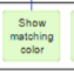 & anter & 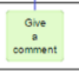 & & & \\
\hline fonesen & 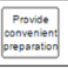 & & & 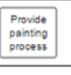 & & & & 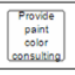 & & & & & 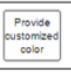 & & \\
\hline 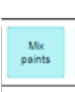 & 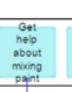 & 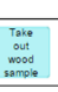 & 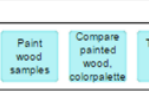 & 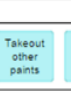 & 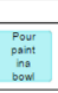 & 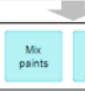 & 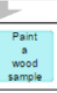 & 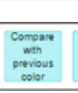 & 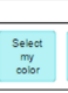 & 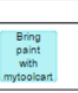 & & & & & \\
\hline & 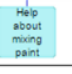 & & & & & & & & & & & 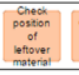 & 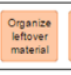 & 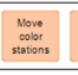 & 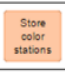 \\
\hline & & & & & & & & & & & & 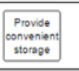 & & & \\
\hline
\end{tabular}

Figure 6. Service blueprint.

\section{in Figure 10.}

\section{Conclusion}

Manufacturing servitization process has been devised with high-level strategy process and low-level specific 


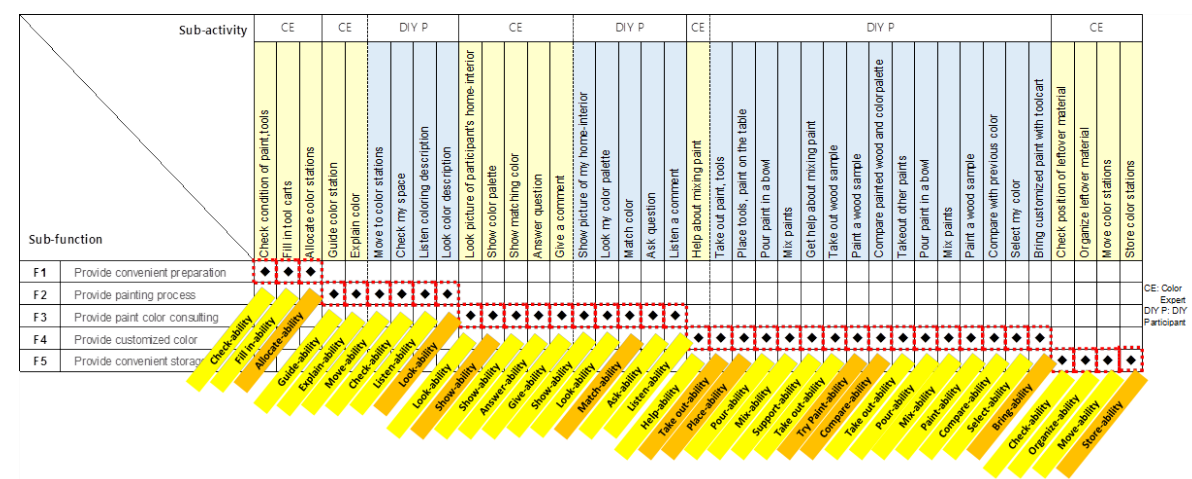

Figure 7. Function-activity interaction and affordances.
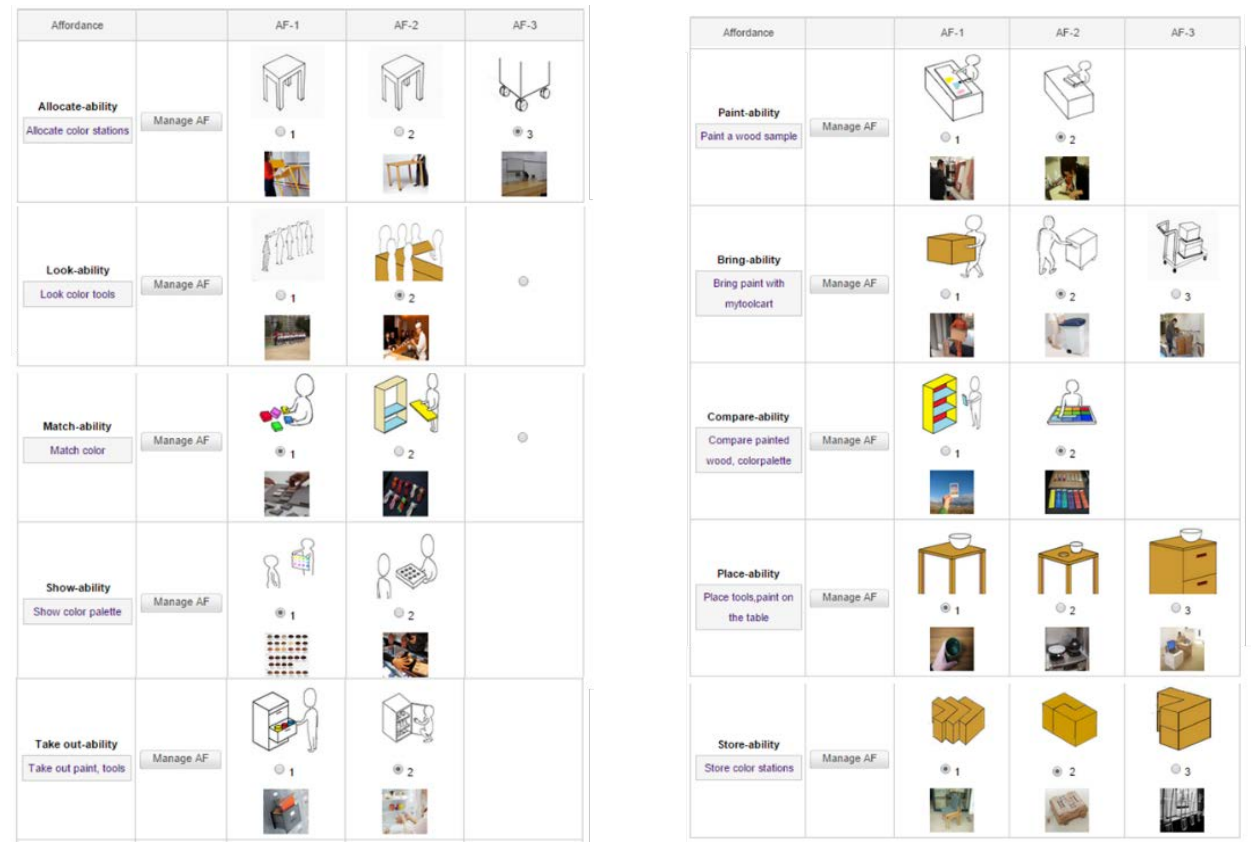

Figure 8. Target affordance feature design.

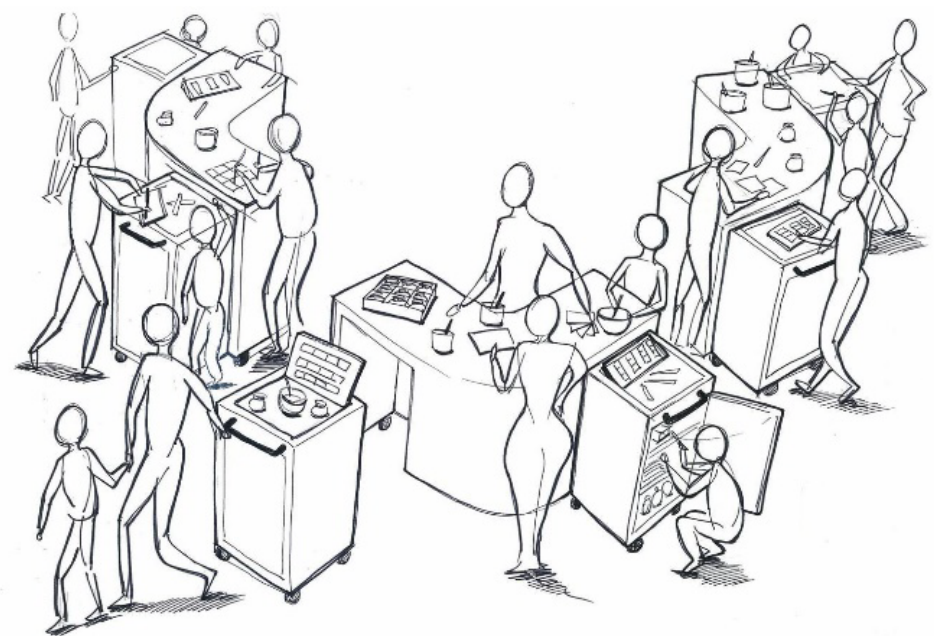

Figure 9. Physical touchpoint design for customized color selection. 


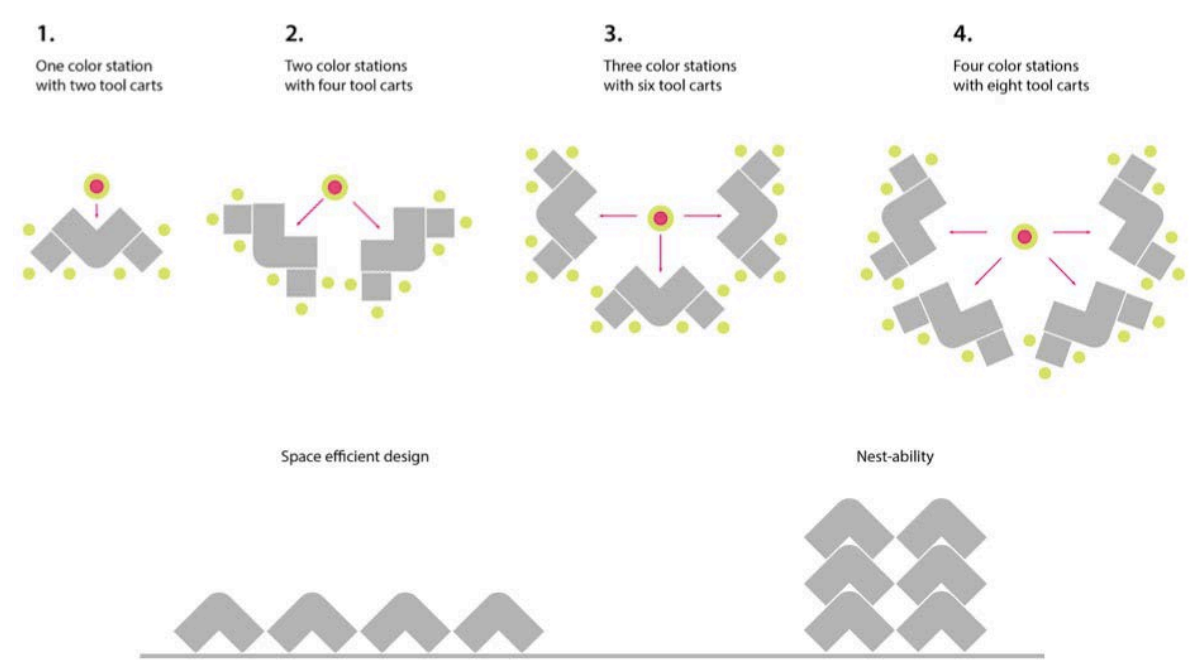

Figure 10. Configurations of color selection station.

product-service systems design. The servitization process has been applied to a small furniture manufacturer and detailed process has been described. Note that product-service systems design and evaluation methods and tools such as service blueprint and customer experience sampling and analysis have be used in an integrated manner. Particular emphasis has been given to ensure that activities of both service receivers and providers are properly induced; a design for affordance method has been applied in designing product element of a critical service touch point. The servitization process will be applied to other real industry cases in the Manufacturing Servitization Support Framework consortium established with support from the Korean Ministry of Trade, Industry, and Energy.

\section{Acknowledgements}

This work has been supported in part by the Korean Ministry of Trade, Industry and Energy, and in part by the Korean Ministry of Education.

\section{References}

[1] Baines, T. and Lightfoot, H. (2013) Made to Serve: How Manufacturers Can Compete through Servitization and Product Service Systems. Wiley.

[2] Krestine., M, Line, N., Adrià, G.M. and Jakob, B.A. (2013) Maritime Branch Analysis: A Workbook in the PROTEUS Series. Technical University of Denmark (DTU).

[3] Cho, C.K., Kim, Y.S. and Lee, W.J. (2010) Economical, Ecological and Experience Values for Product-Service Systems. Proceedings of Design \& Emotion Conference, Chicago.

[4] Kim, Y.S., Lee, S.W., Kim, S.R., Jeong, H. and Kim, J.H. (2012) A Product-Service Systems Design Method with Integration of Product Elements and Service Elements Using Affordances. Proceedings of Service Design and Innovation Conference (ServDes), Helsinki.

[5] Kim, Y.S., Lee, S.W., Jeong, H., Kim, S.R., Kim, J.H., Noh, J.H. and Won, J.H. (2013) A Systematic Design Framework for Product-Service Systems and Its Implementation. International Conference on Service Science and Innovation, Kaoshiung. http://dx.doi.org/10.1109/icssi.2013.22

[6] Kim, Y.S., Shin, J.W., Kim, S.R., Noh, J.H. and Kim, N.R. (2012) A Framework of Design for Affordances Using Affordance Feature Repositories. Proceedings of ASME International Conference on Design Theory and Methodology, Chicago.

[7] Kim, Y.S., Hong, Y.K., Kim, J.H. and Kim, Y.M. (2011) Context-Specific Experience Sampling for Experience Design Research. Proceedings of International Conference on Engineering Design (ICED11), Copenhagen.

[8] Galvao, A.B. and Sato, K. (2005) Affordances in Product Architecture: Linking Technical Functions and Users' Tasks. Proceedings of ASME International Conference on Design Theory and Methodology, Long Beach. http://dx.doi.org/10.1115/detc2005-84525 